\title{
RESEARCH
}

\section{Incidence, severity and preventability of medication-related visits to the emergency department: a prospective study}

\author{
Peter J. Zed PharmD, Riyad B. Abu-Laban MD MHSc, Robert M. Balen PharmD, \\ Peter S. Loewen PharmD, Corinne M. Hohl MD, Jeffrey R. Brubacher MD MSc, \\ Kerry Wilbur PharmD, Matthew O. Wiens BSc(Pharm), Leslie J. Samoy BSc(Pharm), \\ Katie Lacaria BSc(Pharm), Roy A. Purssell MD
}

\section{ABSTRACT}

Background: Medication-related visits to the emergency department are an important but poorly understood phenomenon. We sought to evaluate the frequency, severity and preventability of drug-related visits to the emergency department.

Methods: We performed a prospective observational study of randomly selected adults presenting to the emergency department over a 12-week period. Emergency department visits were identified as drug-related on the basis of assessment by a pharmacist research assistant and an emergency physician; discrepancies were adjudicated by 2 independent reviewers.

Results: Among the 1017 patients included in the study, the emergency department visit was identified as drug-related for 122 patients $(12.0 \%$, 95\% confidence interval [CI] $10.1 \%-$ $14.2 \%$ ); of these, 83 visits ( $68.0 \%, 95 \% \mathrm{Cl} 59.0 \%-76.2 \%$ ) were deemed preventable. Severity was classified as mild in $15.6 \%$ of the 122 cases, moderate in $74.6 \%$ and severe in $9.8 \%$. The most common reasons for drug-related visits were adverse drug reactions (39.3\%), nonadherence (27.9\%) and use of the wrong or suboptimal drug (11.5\%). The probability of admission was significantly higher among patients who had a drugrelated visit than among those whose visit was not drug-related (OR 2.18, 95\% Cl 1.46-3.27, $p<0.001$ ), and among those admitted, the median length of stay was longer (8.o [interquartile range 23.5 ] v. 5.5 [interquartile range 10.0] days, $p=0.06$ ).

Interpretation: More than 1 in 9 emergency department visits are due to drug-related adverse events, a potentially preventable problem in our health care system.

Une version française de ce résumé est disponible à l'adresse www.cmaj.ca/cgi/content/full/I78/I2/I563/DCI

CMAJ 2008;178(12):1563-9

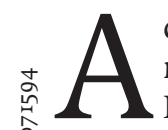

dverse drug-related events are unfavourable occurrences related to the use or misuse of medications. ${ }^{1}$ It has been estimated that such events account for 17 million emergency department visits and 8.7 million hospital admissions annually in the United States. ${ }^{2,3}$ Between I995 and 2000, costs associated with adverse drug-related events rose from US\$76.6 billion to over US\$177.4 billion.,

Adverse drug-related events have recently been evaluated in ambulatory care settings and among patients admitted to hospital, ${ }^{5-9}$ and it has been estimated that $5 \%-25 \%$ of hospital admissions are drug-related. ${ }^{7,8}$ Unfortunately, emergency department visits are not reflected in most hospital studies, because patients seen in the emergency department for an adverse drug-related event are typically not admitted..$^{10}$ In addition, most research evaluating drug-related visits to the emergency department has involved retrospective studies or analysis of administrative data. ${ }^{11-13}$ Retrospective studies may underestimate the incidence of drug-related visits because information may be missing or inaccurately documented. ${ }^{14} \mathrm{Fi}$ nally, studies performed to date have used variable definitions of "drug-related events," ${ }_{1,10}$ which limits comparative evaluation and generalizability.

Despite the burden of drug-related morbidity and mortality, prospective research characterizing drug-related visits to the emergency department has been limited. ${ }^{15-17}$ We sought to overcome some of the limitations of research in this area by using a prospective design and a comprehensive definition of adverse drug-related events. The purpose of this study was to evaluate the frequency, severity and preventability of drugrelated visits to the emergency department of a large tertiary care hospital, to classify the visits by type of drug-related problem and to identify patient, prescriber, drug and system factors associated with these visits.

\section{Methods}

\section{Setting and population}

This prospective observational study was conducted at Vancouver General Hospital, a 955-bed adult tertiary care, referral and trauma centre and a University of British Columbia teaching hospital. The emergency department, where about 69000

From the Department of Pharmacy (Zed), Queen Elizabeth II Health Sciences Centre, Capital Health, Halifax, NS; the Department of Emergency Medicine and College of Pharmacy (Zed), Dalhousie University, Halifax, NS; the Department of Emergency Medicine (Abu-Laban, Hohl, Brubacher, Purssell) and the Pharmaceutical Sciences Clinical Services Unit (Samoy, Lacaria), Vancouver General Hospital, Vancouver, BC; the Faculty of Medicine (AbuLaban, Hohl, Brubacher, Purssell) and the Faculty of Pharmaceutical Sciences (Balen, Loewen, Wiens), University of British Columbia, Vancouver, BC; Pharmacy Services (Balen), Royal Columbian Hospital, New Westminster, BC; Pharmacy Services (Loewen), Vancouver Coastal Health — Providence Health Care, Vancouver, BC; and the Pharmacy Program (Wilbur), Qatar University, Doha, Qatar 
patients are treated annually, is staffed by physicians certified in emergency medicine by the Royal College of Physicians and Surgeons of Canada. The emergency department serves an ethnically diverse inner-city patient population in metropolitan Vancouver. The department is physically separated into 2 areas: "acute care" for major problems and "treatment" for minor problems. ${ }^{18}$ The study was coordinated by the Research Division of the Department of Emergency Medicine. Ethics approval was obtained from the Clinical Research Ethics Board of the University of British Columbia.

\section{Sampling strategy}

All patients who presented to the emergency department during a I2-week period from March I3 to June 4, 2006, were eligible for enrolment. To ensure enrolment of a representative sample of patients, data collection shifts were stratified a priori by day of the week, time of day (0000-0759, 0800-I559, I6oo-2359) and treatment location within the emergency department. Patients who presented during data-collection shifts over the study period were systematically sampled. With the use of a computerized randomization program, one patient was selected from all of the patients who presented in the I-hour period before the start of each data-collection shift. Once the first patient had been randomly selected (at time $t=0$ ), subsequent patients were enrolled at a fixed time interval from the time of presentation of the first patient ( 45 minutes in acute care and 30 minutes in treatment). In situations where a patient was selected but deemed ineligible on the basis of the exclusion criteria (see below), the next patient who presented after the ineligible patient was selected. Data for patients selected for enrolment more than once during the study period were entered as discrete visits. Patients were excluded if they had been transferred from another hospital for specialized care or were returning for a scheduled visit.

\section{Data collection and case definitions}

For each patient, I of 3 residency-trained pharmacist research assistants (M.O.W., L.J.S., K.L.) experienced in the pharmacotherapeutic aspects of adult acute care medicine collected the data using an electronic form (Pendragon Software Corporation, Libertyville, Illinois) accessed through a personal digital assistant. Each pharmacist became familiar with the data-collection process during a 4-week pilot period, and inter-rater reliability for determination of drug-related visits was assessed using 20 sequential assessments on the same patients for each pair of research assistants.

Each patient was interviewed to determine the chief complaint, history of the present illness, past medical history, medication history and allergy status. Medication history included prescription, over-the-counter, and complementary and alternative medications. Additional information was obtained when necessary from family members or other health care providers. PharmaNet, a secure province-wide computer database that links all pharmacies in British Columbia and provides current patient-specific information about prescription medications dispensed in community pharmacies, was used to verify prescription medications. Information from the physical examination conducted by the emergency physician or resident, laboratory results and results of diagnostic tests were used as necessary. Patients were followed up until hospital discharge. During the index emergency department visit, enrolled patients were asked to provide consent for telephone contact I month after discharge to determine progress and evaluate outcomes.

\section{Outcome measures}

An emergency department visit was deemed to be related to medication use if the presentation was directly related to the presenting chief complaint and could be classified into i of 8 predefined drug-related categories: adverse drug reaction, drug interaction, improper drug selection, untreated indication, subtherapeutic dosage, supratherapeutic dosage, nonadherence and drug use without indication (see definitions in Appendix I, available at www.cmaj.ca/cgi/content/full/I78/I2 /1563/DC2). ${ }^{1,19,20}$ If an adverse drug-related event was found incidentally that was unrelated to the presenting chief complaint, the visit was not considered drug-related.

At the point of care, the pharmacist research assistants used 2 electronic clinical-information resources, Lexi-Drugs and Lexi-Interact (Lexi-Comp, Inc., Hudson, Ohio), to obtain drug information, including information about interactions. In addition, the emergency physician responsible for the care of each patient was asked if he or she felt that the visit was drug-related, and if so, the nature of the drug-related cause. Emergency physicians made this assessment without knowledge of the assessment by the pharmacist research assistants.

Causality was determined by both the modified World Health Organization algorithm ${ }^{\mathrm{I}}$ and the modified algorithm of Naranjo and associates. ${ }^{21}$ An adverse drug-related event was considered to be present if assessment by the World Health Organization algorithm indicated a "certain" or "probable" drug-related event, or if assessment by the Naranjo algorithm indicated a "definite" or "probable" drugrelated event.

Severity was classified as mild (laboratory abnormality or symptom not requiring treatment), moderate (laboratory abnormality or symptom requiring treatment or admission to hospital or resulting in nonpermanent disability), severe (abnormality or symptom that was life-threatening or resulted in permanent disability) or fatal. ${ }^{8}$

Drug-related visits were defined as preventable if drug treatment, or lack thereof, was inconsistent with current best practice. Such inconsistencies included inappropriate drug, dosage, route or frequency for the patient's clinical condition, age, weight or renal function; known drug allergy or previous reaction to drug; known drug interaction; nonadherence; lack of laboratory monitoring; and prescribing, dispensing or administration errors. ${ }^{8,10,20,22}$

Cases in which there was discordance in categorization between the pharmacist and the emergency physician were independently adjudicated by 2 external reviewers (one emergency physician and one pharmacist) using explicit criteria and a predefined approach. ${ }^{9,22}$ Standardized case summaries were prepared by the research assistants for these external reviewers. The case summaries included all relevant history obtained during the index visit and, where applicable, infor- 
mation obtained from the I-month follow-up. Each adjudicator determined the likelihood of the visit being drugrelated according to a 6-point Likert scale. If both reviewers rated the visit as 4 (possibly drug-related but more likely due to drug[s]) or higher, the visit was deemed to be drugrelated. If both reviewers rated the visit as 3 (possibly drugrelated but more likely not due to drug[s]) or lower, the visit was deemed not to be drug-related. If there was disagreement in the ratings, the reviewers discussed the case to achieve consensus.

\section{Statistical analysis}

For robust conclusions to be drawn, we initially calculated that we would need a sample size of about 600 acute care patients to achieve a sufficiently narrow $95 \%$ confidence interval $( \pm 3 \%)$ around an anticipated rate of drug-related visits of $21 \%$. However, before the launch of the study, we decided for the purpose of generalizability to include all patients presenting to the emergency department. Since this change would lower the anticipated rate of drug-related visits and require a larger overall sample, and given our anticipation that $5 \%$ of selected patients would be missed because of their leaving the emergency department without being seen, we determined that a I2-week enrolment period would be required to enrol a sufficient number of patients.

We generated descriptive statistics, specifically means and standard deviations or medians and interquartile ranges. The primary outcome of emergency department visits that were drug-related is reported as a percentage with $95 \%$ confidence interval (CI). We performed a comparative analysis of rates of drug-related visits by time of presentation using the $\chi^{2}$ test. Estimates of univariable associations between the occurrence of a drug-related visit and potential patient, prescriber, drug and system variables were reported as odds ratios (ORs) with $95 \%$ CIs.

We performed a stepwise multiple logistic regression to evaluate associations between drug-related visits and patient, prescriber, drug and system factors. Covariates, determined a priori, were age, sex, renal dysfunction (creatinine clearance $<50 \mathrm{~mL} / \mathrm{min}$ ), number of comorbidities, regular family physician, multiple prescribers, number of medications, use of complementary and alternative medications, use of multiple pharmacies and use of an adherence aid (blister pack, dosettes, alarm, calendar or caregiver assistance). All vari-

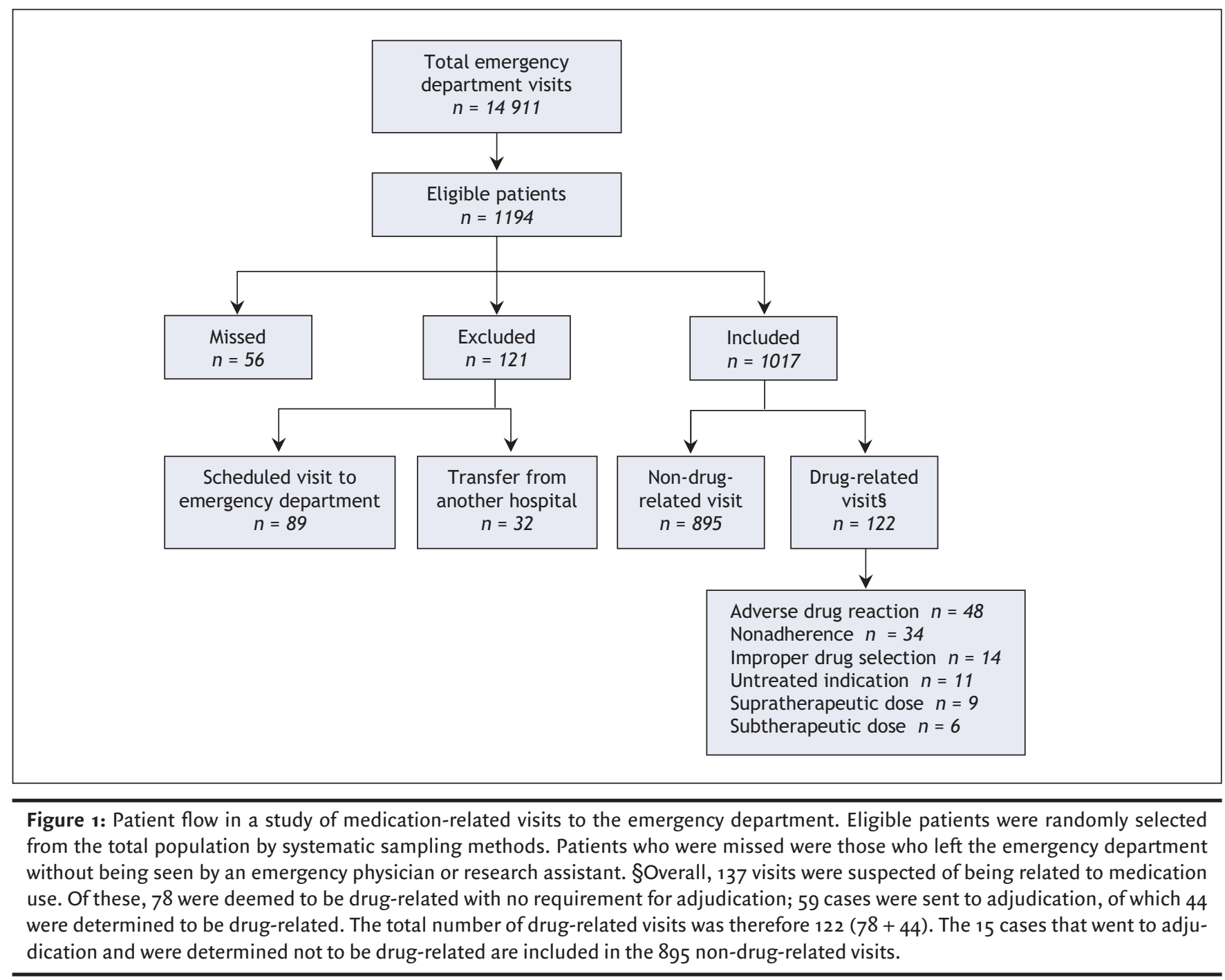


ables with a univariable significance of $p \leq 0.05$ were fitted into the model. We compared length of hospital stay for drug-related and non-drug-related visits using the MannWhitney test.

\section{Results}

During the study period, I4 9II patients presented to the emergency department (Figure I). The mean age of these patients was 49.3 years; $50.7 \%$ were female, $85.0 \%$ had a regular family physician, and $23.3 \%$ were admitted to hospital. Of the II94 patients selected for enrolment, I2I (IO.I\%) were excluded because their visits had been scheduled or because they had been transferred from another hospital, and 56 (4.7\%) left the emergency department without being seen by an emergency physician or research assistant. Thus, we in- cluded IoI7 patients (whose demographic characteristics are presented in Table I) in the final analysis.

During the 4-week pilot period, inter-rater reliability for determining which visits were drug-related was substantial, with kappa scores for the pairs of research assistants of 0.86 , 0.64 and 0.67 . Visits were deemed to be drug-related in $\mathrm{I} 22$ cases (I2.0\%, 95\% CI I0.I\%-I $4.2 \%$ ); of these, 83 (68.0\%, $95 \%$ CI $59.0 \%-76.2 \%$ ) were deemed preventable. Severity was classified as mild in I9 cases ( $15.6 \%, 95 \%$ CI $9.6 \%-$ $23.2 \%)$, moderate in $9 \mathrm{I}$ cases $(74.6 \%, 95 \%$ CI $65.4 \%-82.0 \%)$ and severe in $\mathrm{I} 2$ cases $(9.8 \%, 95 \% \mathrm{CI} 5.2 \%-\mathrm{I} 6.6 \%)$. The most common adverse drug-related events were adverse drug reactions $(39.3 \%$, $95 \% \mathrm{CI} 30.6 \%-48.6 \%)$, nonadherence $(27.9 \%$, $95 \% \mathrm{CI} 20.1 \%-36.7 \%$ ) and wrong or suboptimal drug (II. $5 \%$, $95 \%$ CI $6.4 \%-18.5 \%$ ) (Table 2). The frequency of drug-related visits was unrelated to time of day; such visits occurred dur-

Table 1: Demographic characteristics of 1017 patients with visits to the emergency department for drug-related reasons

\begin{tabular}{|c|c|c|c|}
\hline Characterisitic & $\begin{array}{c}\text { No. (\%) } \\
\text { of patients* }\end{array}$ & Characteristic & $\begin{array}{c}\text { No. }(\%) \\
\text { of patients* }\end{array}$ \\
\hline Age, yr, mean (SD) & $49.6(20.8)$ & Complementary and alternative medication use & $104(10.2)$ \\
\hline$\leq 19$ & $39 \quad(3.8)$ & Yes & $189(18.6)$ \\
\hline $20-29$ & $168(16.5)$ & No & $555(54.6)$ \\
\hline $40-49$ & $168(16.5)$ & No. of pharmacies & \\
\hline $50-59$ & $144(14.2)$ & 1 & $639(62.8)$ \\
\hline $60-69$ & $94 \quad(9.2)$ & $>1$ & 32 (3.1) \\
\hline $70-79$ & $103(10.1)$ & None & $327(32.2)$ \\
\hline$\geq 80$ & $118(11.6)$ & Information not obtained & $19 \quad(1.9)$ \\
\hline Total no. of comorbidities, mean (SD) & $1.7(1.8)$ & $>1$ & $224(22.0)$ \\
\hline No. of comorbidities by category & & None & $287(28.2)$ \\
\hline 0 & $354(34.8)$ & Information not obtained & $2(0.2)$ \\
\hline 1 & $252(24.8)$ & Residence before presentation & \\
\hline 2 & $125(12.3)$ & Home & $978(96.2)$ \\
\hline 3 & $128(12.6)$ & Nursing home or assisted living & $39 \quad(3.8)$ \\
\hline 4 & $67 \quad(6.6)$ & Creatinine clearance, $\mathrm{mL} / \mathrm{min}$ & \\
\hline 5 & $49 \quad(4.8)$ & $\geq 50$ & $445(43.8)$ \\
\hline$>5$ & $42 \quad(4.1)$ & $<50$ & 109 (10.7) \\
\hline $6-9$ & $124(12.2)$ & 4 (< $60 \mathrm{~min})$ & 314 (30.9) \\
\hline$>9$ & $75 \quad(7.4)$ & $5(<120 \mathrm{~min})$ & $125(12.3)$ \\
\hline
\end{tabular}

Note: $\mathrm{SD}=$ standard deviation.

*Unless stated otherwise. 
ing $13.4 \%$ of day visits to the emergency department ( $58 / 433$, $95 \%$ CI I0.3\%-I7.I\%), 9.8\% of evening visits (45/457, 95\% CI $7.3 \%-\mathrm{I} 3.0 \%$ ) and $\mathrm{I} 5.0 \%$ of night visits (I $/ \mathrm{I} 27,95 \% \mathrm{CI} 9.3 \%-$ $22.4 \%)(p=0.15)$.

A total of 179 drugs ( 96 different classes of medication) were implicated in the 122 drug-related visits: for 80 patients (65.6\%), I drug was implicated; for 27 patients (22.I\%), 2 drugs were implicated; and for I5 patients (I2.3\%), 3 drugs were implicated. The most common drug classes were antimicrobial agents (20 [II.2\%]), opioid-containing analgesics (20 [II.2\%]), antipsychotics (I7 [9.5\%]) and benzodiazepines (II [6.I\%]). (For more details about the types of medications associated with the drug-related visits see Appendix 2, available at www.cmaj.ca/cgi/content/full/I78/I2/I563/DC2.)

Of the types of adverse events leading to the 122 drugrelated visits, the most common were neuropsychiatric events (I9 [I5.6\%]), pain (I8 [I4.8\%]) and gastrointestinal reactions (I4 [II.5\%]). (For more details about the types of adverse drug-related events see Appendix 3, available at www.cmaj.ca /cgi/content/full/I78/I2/I563/DC2.)

Overall, $233(22.9 \%)$ of the study patients were admitted to hospital: 45 (36.9\%, 95\% CI $28.3 \%-46.1 \%)$ of the 122 patients whose visit was drug-related and I88 (2I.0\%, 95\% CI I $8.4 \%-$ $23.8 \%$ ) of the 895 patients whose visit was not drug-related. The probability of admission was significantly higher among patients whose visit was drug-related than among those whose visit was not drug-related (OR 2.I8, 95\% CI I.46-3.27, $p<0.00 I$ ). The median length of stay for all admitted patients was 6.0 (interquartile range 12.0) days. The median length of stay was longer for those with a drug-related visit (8.o [interquartile range 23.5] days) than for those without a drugrelated visit (5.5 [interquartile range Io.o] days) $(p=0.06)$.

There were no deaths among patients admitted after a drug-related visit to the emergency department, but there were I4 deaths (7.4\%) among patients admitted after a nondrug-related visit.

Table 2: Classification, preventability and severity of drug-related visits to the emergency department

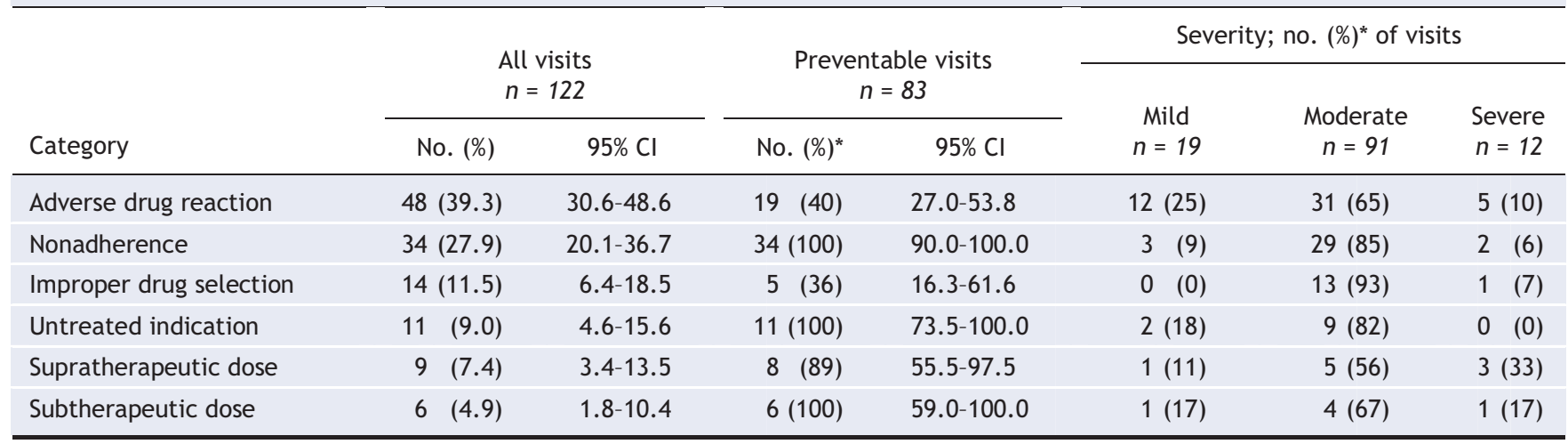

Note: $\mathrm{Cl}=$ confidence interval

*Percentages for preventability and severity are calculated on the basis of the number of visits in each category.

Table 3: Univariable analysis of factors associated with drug-related visits to the emergency department

\begin{tabular}{|c|c|c|c|c|}
\hline Factor & \multicolumn{2}{|c|}{ Type of visit; no. (\%) of visits* } & $\mathrm{OR}(95 \% \mathrm{Cl})$ & $p$ value \\
\hline Age, mean (SD) & $51.9(21.7)$ & $49.3(20.6)$ & $1.01(0.99-1.02)$ & 0.20 \\
\hline Female sex & $62 / 122 \quad(50.8)$ & $468 / 895 \quad(52.3)$ & $1.06(0.73-1.55)$ & 0.76 \\
\hline No. of comorbidities, mean (SD) & $2.5 \quad(1.9)$ & $1.5(1.8)$ & $1.27(1.16-1.39)$ & $<0.001$ \\
\hline $\begin{array}{l}\text { Complementary and alternative } \\
\text { medication use }\end{array}$ & $8 / 117 \quad(6.8)$ & $96 / 866 \quad(11.1)$ & $0.59(0.28-1.29)$ & 0.17 \\
\hline Use of adherence aid & $33 / 102 \quad(32.4)$ & $156 / 642 \quad(24.3)$ & $1.49(0.94-2.32)$ & 0.08 \\
\hline$>1$ pharmacy & $6 / 119 \quad(5.0)$ & $26 / 879 \quad(3.0)$ & $1.74(0.70-4.33)$ & 0.23 \\
\hline Regular family physician & $104 / 122 \quad(85.2)$ & $731 / 895 \quad(81.7)$ & $1.30(0.76-2.17)$ & 0.34 \\
\hline
\end{tabular}

Note: $\mathrm{OR}=$ odds ratio.

*Unless stated otherwise. 
In the univariable analysis, the number of comorbidities, the number of medications and the use of multiple prescribers were significantly associated with drug-related visits (Table 3). In the multivariable adjusted analysis, only the number of medications was independently associated with drug-related visits (OR I.07, 95\% CI I.OI-I.I3, $p=0.02$ ).

\section{Interpretation}

In this study, we found that adverse drug-related events accounted for $12.0 \%$ of emergency department visits, of which $68.0 \%$ were considered preventable. Rates of hospital admission were higher and length of stay appeared to be longer among patients whose visits were drug-related than among patients who presented for other reasons. The prospective design of this study, its large sample, the use of causality assessment tools and assessment by an independent adjudication committee increase the likelihood that our estimates of drug-related visits and their preventability are accurate. In addition, our use of a systematic sampling strategy and a priori enrolment stratification increases the generalizability of our findings.

The percentage of drug-related visits in this study was higher than that in most previous reports. ${ }^{11}$ This result may be explained by a number of factors. First, the prospective design and follow-up at I month after the index visit allowed complete medical and medication histories to be obtained and ensured that we had the information required to accurately classify the cases. Second, we used experienced clinical pharmacists trained in the recognition and resolution of drug-related problems and considered their assessment in combination with that of an independent emergency physician. Previous work has shown that emergency physicians recognize adverse drug-related events at a rate of about $50 \%$; therefore, studies that rely solely on physicians' assessment underestimate the incidence of drug-related visits. ${ }^{13}$ Finally, use of a comprehensive classification system increased the likelihood that all drug-related causes of emergency department visits were identified. Our inclusion of nonadherence to a medication regimen as a drug-related reason for an emergency department visit is unique and reflects our belief that this problem should be included in estimates of the burden of drug-related visits.

The classifications according to type of drug-related problem, specific drug therapies and high rate of preventability identified in our study are consistent with findings from previous reports. ${ }^{10,23}$ Although the overall hospital admission rate was also consistent with previous reports, the higher admission rate among patients whose visit was drug-related was striking. It remains unclear whether this represents an association, causation or both. Adverse drug-related events often require time and monitored observation for treatment or resolution, and hospital admission may therefore be indicated for a greater proportion of such visits. Specific risk factors for drug-related visits have been inconsistently identified in the literature. ${ }^{\mathrm{IO}}$ In our study, only the number of medications was independently associated with drug-related visits. This result was not surprising, since a greater number of medications would increase the potential for adverse drug re- actions and poor adherence. Minimizing the total number of medications that individual patients receive might therefore reduce drug-related visits to the emergency department. It is interesting that our secondary analysis suggested the possibility of a variation by time of day, with the highest rate occurring during the night (0000-0759). If this statistically nonsignificant finding is real, it may reflect differences in the patient population that visits the emergency department overnight and lack of access to other health care resources at that time of day.

Our study has several limitations. First, although the research assistants used a standardized approach, bias may have occurred in the determination of whether a visit was drug-related. We attempted to minimize this potential bias through an independent adjudication process. Second, although a standardized approach was used in the formulation of the adjudication case summaries, bias might also have been introduced at this stage. In addition to reviewing the case summaries, adjudicators had access to all relevant medical records and made their assessments without knowledge of the determinations of the pharmacists or emergency physicians. Third, increased attention to the subject of drug-related visits resulting from this study may have heightened emergency physicians' awareness of drug-related issues and introduced a Hawthorne effect. Fourth, the I2-week study period did not allow exploration of any seasonal variation in drugrelated presentations. Finally, given the study location, our results are not necessarily generalizable to community, rural or pediatric hospitals.

Future research should focus on interventions to optimize communication between health care professionals in acute and ambulatory settings and to improve patients' adherence with prescribed medications. ${ }^{24}$ It should also explore the higher admission rate among patients with drug-related visits and determine whether such visits represent a marker of sicker patients or an independent factor leading to an increased likelihood of hospital admission. The optimal strategy may involve interventions outside the hospital to improve prescribing practices and monitoring, particularly among high-risk patients or patients taking high-risk medications. ${ }^{25}$

In conclusion, more than $\mathrm{I}$ in 9 emergency department visits are due to drug-related adverse events, a potentially preventable problem in our health care system.

\section{This article has been peer reviewed.}

Competing interests: None declared.

Contributors: The study was conceived and designed by Peter Zed, Riyad Abu-Laban, Robert Balen, Peter Loewen, Corinne Hohl, Jeffrey Brubacher, Kerry Wilbur and Roy Purssell. Peter Zed, Robert Balen, Matthew Wiens, Leslie Samoy and Katie Lacaria were responsible for data acquisition; Peter Zed, Riyad Abu-Laban, Robert Balen and Peter Loewen for analysis and interpretation of data; and Peter Zed, Riyad Abu-Laban, Robert Balen and Peter Loewen for drafting the manuscript. All authors made critical revisions to and gave final approval of the manuscript. Peter Zed, Riyad Abu-Laban and Robert Balen contributed to the statistical analysis; Peter Zed, Riyad AbuLaban, Robert Balen, Corinne Hohl, Jeffrey Brubacher and Roy Purssell obtained funding for the study; Peter Zed, Riyad Abu-Laban, Robert Balen, Peter Loewen, Kerry Wilbur, Matthew Wiens, Leslie Samoy and Katie Lacaria provided administrative, technical and material support; and Peter Zed was responsible for overall supervision of the study. 
Acknowledgements: We thank Michael Schulzer MD PhD, Centre for Clinical Epidemiology and Evaluation, Vancouver Coastal Health Research Institute, Vancouver, BC, and Edwin Mak, Pacific Parkinsons Research Centre, University of British Columbia, Vancouver, BC, for their statistical support; Sean Gorman PharmD, Vancouver General Hospital, Vancouver, BC, and Frank Scheuermeyer MD, St. Paul's Hospital, Vancouver, BC, for serving as members of the adjudication committee; Jan Buchanan, Department of Emergency Medicine, Vancouver General Hospital, for administrative support; Neil MacKinnon PhD, Dalhousie University, Halifax, NS, for editorial assistance in the preparation of the manuscript; and the emergency physicians at Vancouver General Hospital for their support throughout the study.

This study was supported by the Vancouver General Hospital and University of British Columbia Hospital Foundation through the in it for life Fund. The funding organization was not involved in the design or conduct of the study; the collection, management, analysis or interpretation of the data; or the preparation, review or approval of the manuscript. During the study period, Riyad Abu-Laban was supported by a Clinical Scholar Award from the Michael Smith Foundation for Health Research. Corinne Hohl is supported by a Mentored Clinical Scientist Award from the Vancouver General Hospital and University of British Columbia Hospital Foundation's in it for life Fund.

This study was presented at the Annual Scientific Meeting of the Canadian Association of Emergency Physicians, June 2-6, 2007, Victoria, BC.

\section{REFERENCES}

I. Nebeker JR, Barach P, Samore MH. Clarifying adverse drug events: a clinician's guide to terminology, documentation, and reporting. Ann Intern Med 2004;140:795-80I

2. Bates DW, Spell N, Cullen DJ, et al. The costs of adverse events in hospitalized patients. JAMA I997;277:307-II.

3. Johnson JA, Bootman JL. Drug-related morbidity and mortality: a cost of illness model. Arch Intern Med I995;155:1949-56.

4. Ernst FR, Grizzle AJ. Drug-related morbidity and mortality: updating the cost-ofillness model. JAm Pharm Assoc (Wash) 200I;41:192-9.

5. Lazarou J, Pomeranz BH, Corey PN. Incidence of adverse drug reactions in hospitalized patients: a meta-analysis of prospective studies. JAMA I998;279:1200-6.

6. Gurwitz JH, Field TS, Harrold LR, et al. Incidence and preventability of adverse drug events among older persons in the ambulatory setting. JAMA 2003;289:1107-I6.

7. Samoy LJ, Zed PJ, Wilbur K, et al. Drug-related hospitalizations in a tertiary care internal medicine service of a Canadian hospital: a prospective study. Pharmacotherapy 2006;26:1578-86.

8. Pirmohamed M, James S, Meakin S, et al. Adverse drug reactions as a cause of ad- mission to hospital: prospective analysis of I8 820 patients. BMJ 2004;329:15-9.

9. Baker GR, Norton PG, Flintoft V, et al. The Canadian Adverse Events Study: the incidence of adverse events among hospital patients in Canada. CMAJ 2004;170:1678-86.

Io. Zed PJ. Drug-related visits to the emergency department. J Pharm Pract 2005; I8: 329-35.

II. Budnitz DS, Pollock DA, Weidenbach KN, et al. National surveillance of emergency department visits for outpatient adverse drug events. JAMA 2006;296:1858-66.

I2. Budnitz DS, Shelab N, Kegler SR, et al. Medication use leading to emergency department visits for adverse drug events in older adults. Ann Intern Med 2007;147:755-65.

13. Hohl CM, Robitaille C, Lord V, et al. Emergency physician recognition of adverse drug-related events in elder patients presenting to an emergency department. Acad Emerg Med 2005;12:197-205.

I4. Nagurney JT, Brown DF, Sane S, et al. The accuracy and completeness of data collected by prospective and retrospective methods. Acad Emerg Med 2005;I2:884-95.

I5. Tafreshi MJ, Melby MJ, Kaback KR, et al. Medication-related visits to the emergency department: a prospective study. Ann Pharmacother 1999;33:1252-7.

I6. Hohl CM, Dankoff J, Colacone A, et al. Polypharmacy, adverse drug-related events, and potential adverse drug interactions in elderly patients presenting to an emergency department. Ann Emerg Med 200I;38:666-71.

I7. Queneau P, Bannwarth B, Carpentier F, et al. Emergency department visits caused by adverse drug events: results of a French Study. Drug Saf 2007;30:8I-8.

I8. Beveridge R, Clarke B, Janes L, et al. Canadian Emergency Department Triage and Acuity Scale: implementation guidelines. Can J Emerg Med I999;I(3 Suppl):S2-S24.

I9. Hepler CD, Strand LM. Opportunities and responsibilities in pharmaceutical care. Am J Hosp Pharm 1990;47:533-43.

20. Hallas J, Harvald B, Gram LF, et al. Drug related hospital admissions: the role of definitions and intensity of data collection and the possibility of prevention. J Intern Med I990;228:83-90.

2I. Naranjo CA, Busto U, Sellers EM, et al. A method for estimating the probability of adverse drug reactions. Clin Pharmacol Ther 1981;30:239-45.

22. Forster AJ, Clark HD, Menard A, et al. Adverse events among medical patients after discharge from hospital. CMAJ 2004;170:345-9.

23. Winterstein AG, Sauer BC, Hepler CD, et al. Preventable drug-related hospital admissions. Ann Pharmacother 2002;36:1238-48.

24. Boockvar K, Fishman E, Kyriacou CK, et al. Adverse events due to discontinuation in drug use and dose changes in patients transferred between acute and long-term care facilities. Arch Intern Med 2004;164:545-50.

25. Shojania KG. Safe medication prescribing and monitoring in the outpatient setting. CMAJ 2006;174:1257-9.

Correspondence to: Dr. Peter J. Zed, Queen Elizabeth II Health

Sciences Centre, Department of Pharmacy - Halifax Infirmary, I796 Summer St., Halifax NS B3H 3A7; fax 902 473-3904;

peter.zed@dal.ca 